attended with beneficial results; and although the man was low and his reparative powers were much reduced, in spite of a generous diet and tonics, he seemed likely to be soon well.

May - In the early part of this month the man was rather suddenly seized with great constitutional disturbance, which resembled the commencement of an attack of pyæmia. It seemed, however, to be produced by some local inflammatory action, for after a more profuse escape of pus from the perineal opening the man rallied. From this date (about the middle of May) he gradually improved in health, the discharge of pus diminished, and he left the hospital on June 9th, well. At the time of his exit the penis was of normal size.

The recovery of this patient would have taken place about the middle of February, or in about a month after the extravasation of blood occurred, had not suppuration arisen, to which cause his protracted convalescence must be referred. From the moment of his admission Mr. Birkett determined to treat the case on the principle adopted in all swellings resulting from extravasation of blood : that is, to leave the repair of the injury to the efforts of nature, and not to interfere with the process of absorption. The man, however, complained so bitterly of the pain caused by the distension of the organ, that the incision was made for the purpose of affording relief mechanically - a practice Mr. Birkett would not again adopt.

The first case was recorded by Mr. Callaway in 1824 . (London Medical Repository, 1824, p. 286.) The man was forty-four years old; and, whilst intoxicated, had connexion with his wife. The state of the penis was exactly similar to that above described; and the priapism had continued unchanged for sixteen days, when Mr. Callaway made an opening into the left crus penis below the scrotum, and a large quantity of dark, grumous blood with small coagula escaped. The corpora cavernosa were emptied, and a few days afterwards the man was able to follow his work.

The second case is published in THE LANCET of July, 1845, and is described by Mr. John W. Tripe, of Hackney, under whose treatment he continued for four days, and was then admitted into the London Hospital, under the care of Mr. Luke. The man was a sailor, aged twenty-six years. The priapism continued after frequent connexion, and was persistent for about four months. In course of time the blood appears to have been absorbed, and the functions of the organ to have become perfectly restored. This man left the hospital after being therein only ten days, and the further progress towards recovery was unassisted by surgical art.

To these another may be added which we saw recently in St. Mary's Hospital, under the care of Dr. Handfield Jones, and in which, after persistence of the symptoms for a month, relief was obtained by an incision made by Mr. Haynes Walton into the corpus cavernosum of one side. As we understand Dr. Handfield Jones is about to publish particulars of this interesting esse, we shall refrain from referring to its details.

\section{THE LONDON INFIRMARY FOR EPILEPSY AND PARALYSIS.}

CASES OF EPILEPSY WTTH COMPLTCATIONS; REMARKS UPON TREATMENT.

(Under the care of Dr. Althaus.)

THERE are certain complications of epilepsy which have hitherto escaped the attention of pathologists, although they appear to be by no means rare, and have an influence upon the progress of the cases in which they may happen to be present, inasmuch as their neglect may defeat our other therapeutical efforts, however perseveringly followed. Amongst these complications, Dr. Althaus, in some remarks about the etiology and progress of epilepsy, mentioned chiefly the occiurrence of hay fever and of congenital phimosis in males.

Hay fever was a form of catarrh in which the symptoms of spasm predominated over those of inflammation, and which was mainly due to irritation of the sentient nerves of the respiratory tract, consequent upon the inhalation of the gases arising from fresh grass and hay. The nerves suffered more in this disorder than the mucous membrane, for there were often fits of sneezing which lasted for an hour or more with scarcely any interruption, and such urgent dyspncea as could not be explained merely by the slight catarrhal affection of the air-passages. Hay fever was in nowise a dangerous disorder, but tended considerably to irritate and lower the tone of the nervous centres; and if it appeared in an epileptic patient, it almost always meant mischief, aggravating the attacks if such still occurred, and predisposing to relapses where the attackg had been put down. Being an essentially spasmodic disorder, it was best treated by sedatives, whereby it was generally re. moved in a very short time. After the symptoms of irritation had subsided, the administration of tonies was usually found necessary.

Sarah S-, aged twenty-eight, single, came under treatment as an out-patient on March 21st, 1866. She has for the last five years suffered from epileptic fits, with prolonged loss of consciousness and severe convulsions. The origin of the fits she attributed to a severe attack of small-pox, which she had in the spring of 1861 , and which prostrated her a great deal. She has at present from four to six epileptic fits during the week, some in the day-time, and some at night. Those which occur in the day are ushered in by visions of large black specks floating about in the air; a sort of faintness then comes over her, which rapidly passes into unconsciousness and con. vulsions. When she has a night-fit she generally dreams that she is falling, and on waking finds her tongue severely bitten, and feels bruised in the limbs. Emotions have no influence on the occurrence of these attacks. She sleeps very badly, and has horrible dreams, especially about the dead. She often suffers from headache and giddiness. Appetite indifferent; bowels habitually costive. She has lost a good deal of flesh lately, and presents a worn and anæmic appearance. She suffers from palpitations of the heart, and shortness of breath in walking; an anæmic murmur is heard over the base of the heart. The catamenia are pretty regular, although pale and scanty ; a short time before the period comes on the fits are more frequent and severe.

The patient was put on a course of phosphorus, tincture of henbane, and cod-liver oil, under which the attacks steadily diminished in number and severity. The last occurred on May 6th. Her strength and general appearance were then very much improved, and she went on favourably till June 29th, when she was seized with a sharp attack of hay fever of which she has been suffering every summer for the last seven or eight years. There was burning in the eyes, catarrh in the nose, a feeling of rawness in the throat, and very con. siderable dyspnoea. During the day she was obliged to stop in-doors and have the room shaded and the windows closed, but she could go out in the evening.

On July 11th, the patient being then very restless and worn out by fits of sneezing and dyspncea, an epileptic attack oo. curred, in the day-time, after a free interval of sixty-four days. On the 12th she had another bad attack, during the early part of the night. She was very weak and low-spirited. A draught, containing five minims of the dilute hydrocyanic acid and fifteen minims of tincture of Indian hemp, was then given, in mucilage, twice a day, and the other medicines were discontinued The distress from the hay fever was now at once greatly diminished, and after taking the draught for four days it quite ceased. No further epileptic attacks took place; and the patient got quite well again under the use of nerve-tonics.

She was seen on September 26th, being then in excellent health and spirits, and having had nothing to complain of in the interval. It remains to be seen whether the attacks have finally ceased; yet the prejudicial influence of hay fever on the progress of this, as of other similar cases, is obvious.

Congenital phimosis has been observed in eleven out of twenty-five consecutive male cases of epilepsy admitted at the infirmary. That such a frequent complication of epilepsy should hitherto have remained unnoticed can only be explained by the circumstance that epileptic patients seldom come under the eye of surgeons, and that physicians usually neglect to examine the sexual organs. The effects of congenital phimosis on the system are usually quite disregarded, although there can be little doubt that this malformation has a considerable patholo. gical importance. There is always an accumulation of sebum between the prepuce and the gland in such cases, and herpes and balanitis may be the consequence. This irritation often leads to great sexual excitement about the period of puberty, and to masturbation, with all its consequent evil effects; frequent emissions of semen at night may also be traced to the same cause. A variety of cerebral symptoms may then be induced, such as pain in the head, giddiness, noises in the ears, eructations, sickness, \&c.; which, where they depend only upon this condition, may be entirely removed by circumcision Whether actual epileptic fits are ever the consequence of phimosis seems doubtful; yet the propriety of the operation in cases of that kind cannot be questioned, as all sources of irri. tation should, on principle, be removed in convulsive disorders. Several of these cases which were admitted at the infirmary 
have been operated upon by Mr. Solly and Mr. Spencer Wells. In no instance, however, have the fits ceased immediately, consequent upon the operation; so that a relation as between cause and effect could not have existed between phimosis and epilepsy. Yet, Dr. Althaus said, it generally seemed as if the convulsive disorder, after circumcision in such cases, yielded more readily to the remedies employed than it had done before,

\section{FROST ACCIDENTS IN SOME OF THE METROPOLITAN HOSPITALS.}

A LARGE number of persons met with accidents during the late frost, especially on the memorable night of Tuesday, the 22nd of January, when the streets were covered with frozen rain.

From St. Bartholomew's Mr. R. Bond Moore, house-surgeon, gives us the following list of the more severe accidents : Scalp wounds, 5 ; fractures of humerus, 2 ; dislocations of humerus, 4 ; fractures of radius and ulna, 3 ; fractures of radius, 5 ; fractured ulna, $L$; fractures of metacarpal bone of thumb, 2 ; dislocated thumb, 1 ; compound fracture of tibia and fibula, 1 ; fractured fibula, 1. Of the five who received scalp wounds, two were admitted, one with concussion, and another with rather severe arterial hæmorrhage. In two of the fractures of both bones of the forearm there was considerable displacement-in fact, they were all but compound. The above list, with injuries of a more trivial nature, and all traceable to the rain of Tuesday, followed by frost, includes a total number of 117 patients. Besides these, there was an almost endless number of sprains (principally of the wrist and ankle joints), and contusions of various parts. Much praise is due to the dresser on duty, Mr. W. Wingate Saul, who with untiring energy continued to relieve patients through the whole night.

During the week ending Jan. 23rd the following accidents from various causes were admitted into $G u y^{\prime} s$, under $\mathrm{Mr}$. Poland's care. Mr. Buck, dresser, has obliged us with the list.

Jan. 16th. - M. H., female, aged fifty-one; lacerated and contused wounds of right hand. - M. J., female, aged fiftyfour; fractured tibia and fibula. - E. $R_{0}$, male, aged three; severe burn of chest and abdomen; dead. -J. H., male, aged eight; burn of chest, abdomen, neck, back, and arm.-T. M., male, aged fifteen; concussion of brain. - G. C., male, aged twenty-nine; pistol-shot wound of lower third of left thigh, causing comminuted fracture of femur ; amputation.

Jan. 17th.-F. B., male, aged thirty; separation of first and second pieces of sternum. - J. S., male, aged sixty-three; fractured tibia and fibula. - M. Y., female, aged forty-four; femoral hernia.

Jan. 18th.-D. C., male, aged twenty; severe laceration of upper third of left thigh and buttock, minor laceration of right thigh; dead. This patient was caught between some cogged wheels. During life, by looking through any of the lacerations of the buttock, one could see completely through the limb to the inner side of the thigh. Dissection showed that the only structures remaining were the shaft of the femur, the femoral artery, sciatic nerve, a few fibres of the rectus muscle, and the greater portion of the skin; in addition, there were severe lacerations of the penis and scrotum. - M. Y., female, aged thirty-nine ; fracture of femur (lower third).

Jan. 19th. - D. W., male, aged twenty-nine; contusion of back. - H. D., male, aged twelve; compound fracture of finger and lacerations of hand. - J. C., male, aged thirteen ; acute synovitis of knee-joint after injury.-I. C., female, aged fifteen; ; contusion of toes.

Jan. 20th.-J. H., male, aged three; fractured tibia.

Jan. 2lst. - J. J., male, aged seventy-six ; strangulated femoral hernia ; operation; dead.-W. M., male, aged twelve; contused abdomen. - J. C., male, aged sixty-one; dislocation of left femur into sciatic notch ; fracture of eighth, ninth, and tenth ribs on left side; fracture of right fibula, and right internal malleolus knocked off.

Jan. 22nd. - M. H., fernale, aged two; extensive burns. J. C., male, aged twenty-seven; compound fracture of tibia and fibula.-J. O., male, aged thirty-four; compound fracture of tibia and fibula; dead.-H. L., male, aged forty-six; fractured patella.-W. B., male, aged sixty-four; fractured neck of femur. -W. $\$$., male, aged forty-five; fractured patella.H. K., male, aged fifty-three; comminuted fracture of tibia and fibula.-D. M., male, aged eighteen ; contused foot.

Jan, 23rd, - W. M., male, aged nineteen; compound frac- ture of tibia and fibula, extending into ankle-joint ; amputation. - E. D., female, aged fifty-six; fracture of radius and ulna of both arms, contusion of scalp, and laceration of perineum.-A. S., female, aged twenty-two ; fractured fibula.

At St. George's, amongst others, the following very interesting case was admitted. For particulars of it we are indebted to Mr. E. C. Ring, surgical registrar.

E. $\mathrm{O}-$ aged thirty-nine, labourer, was admitted on the 18th, under the care of Mr. Prescott Hewett. He had been engaged in excavating, when a large mass of earth, from being bound together by the frost, suddenly fell en masse without warning, forcing the man against the side of the cutting, and driving the handle of the pick he was working with through his left thigh and pinning him to the earth. The handle was broken off close to the iron, and the man could only extricate himself by drawing his thigh from the wood, which he left in the cutting.

On admission, there was a wound in the left thigh, about four inches below Poupart's ligament, on the inner side of the femoral vessels, its edges being bruised and irregular. On the posterior aspect of the limb was another similar wound, about five inches and $a$ half below the great trochanter, and internal to it. The pulsations of the femoral and tibial arteries were quite normal. There was no hæmorrhage, and but little pain. The limb was placed on an inclined plane, and, though some swelling followed, the man has been doing well. The broken handle of the pick is $20 \frac{1}{2}$ in. in length, $5 \frac{\pi}{8}$ in. in circumference at one extremity, and $4 \frac{y}{8}$ in. at the other. A little redness and swelling near the wounds which existed for a few days subsided. The wound on the upper and inner part of the thigh is nearly well ; but in the one below there is suppuration, and near it a small hard lump, as if some portion of clothing had been left there. On Feb. 3rd he complained of his jaws feeling stiff, but that Mr. Hewett believes to have been due to nervousness, from seeing a man with trismus lying near him; and since his removal to another bed he has reco. vered.

The escape from injury of the femoral artery is very remarkable. Mr. Hewett mentioned to us two cases of analogous character which had come under his care. A man in climbing over the park railings fell, and his thigh was torn up from one end to the other by a spike. In another instance the patient was on horseback, and was caught by the shaft of a Hansom cab, which tore open the groin and upper part of thigh. In neither case was there injury to large vessels.

\section{CLINICAL RECORDS.}

\section{REPEATED RESECTION OF THE KNEE-JOINT.}

SEVERAL cases have occurred in which delay in healing, and the evident occurrence of necrosis after resection, has rendered a second operation necessary. At King's College Hospital, under such circumstances, it is thought better to repeat the resection rather than to amputate the thigh. Sir William Fergusson has had three or four such cases, which have done well; and Mr. H. Smith had one in which the proceeding answered perfectly. On Saturday last Mr. Smith again adopted the plan in the case of a lad whose knee-joint he had excised in July last. The boy went on well at first, then fell back, and was sent into the country for a few months-not to much purpose however, for sinuses about the wound persisted, and showed the presence of dead bone, and the boy's health was suffering from the prolonged irritation. On opening up the wound, firm anchylosis was found to a limited extent between the femur and tibia. Lying behind the former bone was a ragged sequestrum, an inch or two long, representing the intercondyloid space of the femur - that portion of bone which is so often exposed to necrosis. There was an abscess in the head of the tibia. Mr. Smith removed a thin section of this latter bone and a portion of femur, and brought the bones into apposition again just as in ordinary resection. When the sequestrum came to be examined, an old arterial ligature was found lying about it. This must have been accidentally dropped into the wound in July last, at the time of operation, and there it had since rested. Was it the presence of this piece of string which excited in. flammation leading to the death of the shell of bone described?

\section{CANCER OF THE TONGUE.}

We saw Mr. Paget cut away about one-fourth of an old man's tongue on Saturday, in the operating theatre of St. Bar. 